\title{
A encenação e a melancolia em "O Mágico"
}

The staging and the melancholy in "L'illusionist

\begin{abstract}
ANDREO, Marcelo Castro; Mestre; Universidade Estadual de Londrina marceloandreo@gmail.com
\end{abstract}

\section{Resumo}

Este artigo trata das técnicas de encenação no longa-metragem francês de animação O Mágico, de Sylvain Chomet, e as relações entre as escolhas estilísticas deste diretor e a melancolia como um aspecto do moderno segundo os ensaios de Walter Benjamim e Marshall Berman.

Palavras-Chave: Animação; Staging; Cinema.

\begin{abstract}
This paper deals with the techniques of staging in the French feature film animation The Illusionist, by Sylvain Chomet and the relationship between the stylistic choices of the director and melancholy as an aspect of the modern according to the writings of Walter Benjamin and Marshall Berman.
\end{abstract}

Keywords: Animation; Staging; Cinema.

\section{Introdução}

O filme de animação O Mágico, do diretor francês Sylvain Chomet (2010), possui óbvios méritos artísticos: na animação bastante verossímil, seguindo o melhor estilo "illusion of life" dos estúdios Disney e no design de personagens que, por sua vez, nada guarda em semelhança com o modo Disney de se criar personagens amigáveis, infantilizados e culturalmente determinados como "bonitos" ${ }^{1}$. Sua narrativa e a atuação dos personagens busca inspiração em outras fontes fora da animação; em especial, a filmografia de Jacques Tati.

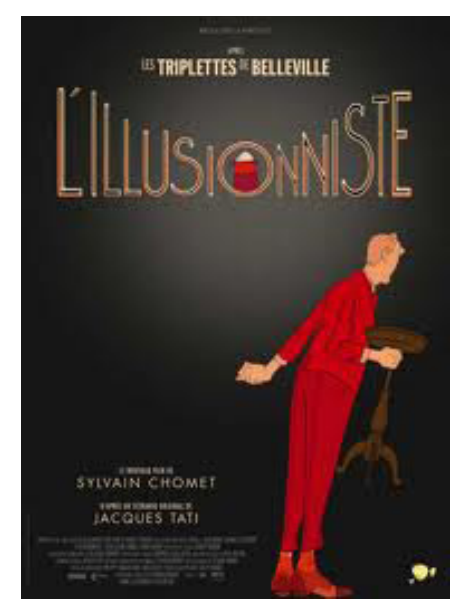

Figura 1 - Cartaz de Filme

Fonte: The Internet Movie Database (2011) 
A encenação e a melancolia em "O Mágico"

Neste artigo analisa-se o filme $\mathrm{O}$ mágico, de Chomet, a partir das similaridades entre a narração contida neste filme e a observação do moderno (e a melancolia decorrente do mesmo) na visão de diferentes autores: de suas características vistas na obra de Walter Benjamim a respeito de Paris e de Baudelaire; da análise de Berman a respeito da natureza do moderno a partir dos escritos de autores do final do século XIX, e das opções estilísticas quanto à encenação (staging) utilizadas para corroborar a narrativa deste filme.

Além das qualidades visíveis na superfície da animação de Chomet, podem se encontrar outras facetas a serem descobertas e que são contadas a partir da narrativa contida neste filme. O mágico Tatischeff tem os maneirismos do Monsieur Hulot, personagem de uma série de filmes de Jacques Tati nos anos 1950-60, entre eles, o conhecido O roteiro deste filme foi uma adaptação de um texto não filmado de Jaques Tati, e o autor-diretor teve a preocupação de manter as características que marcaram a carreira de Tati, um espírito de filme mudo na época do cinema sonoro, com ênfase nas pantomimas, na mímica e na expressão corporal: o rosto e o corpo dos atores, aliado a bem pensada sequência de planos (Fig. 2).

Nessa atividade do contar uma história, várias outras camadas de significado podem ser encontradas e lidas através das atuações dos personagens, da melancólica trilha sonora e da mistura entre comédia e drama presente nesta obra.

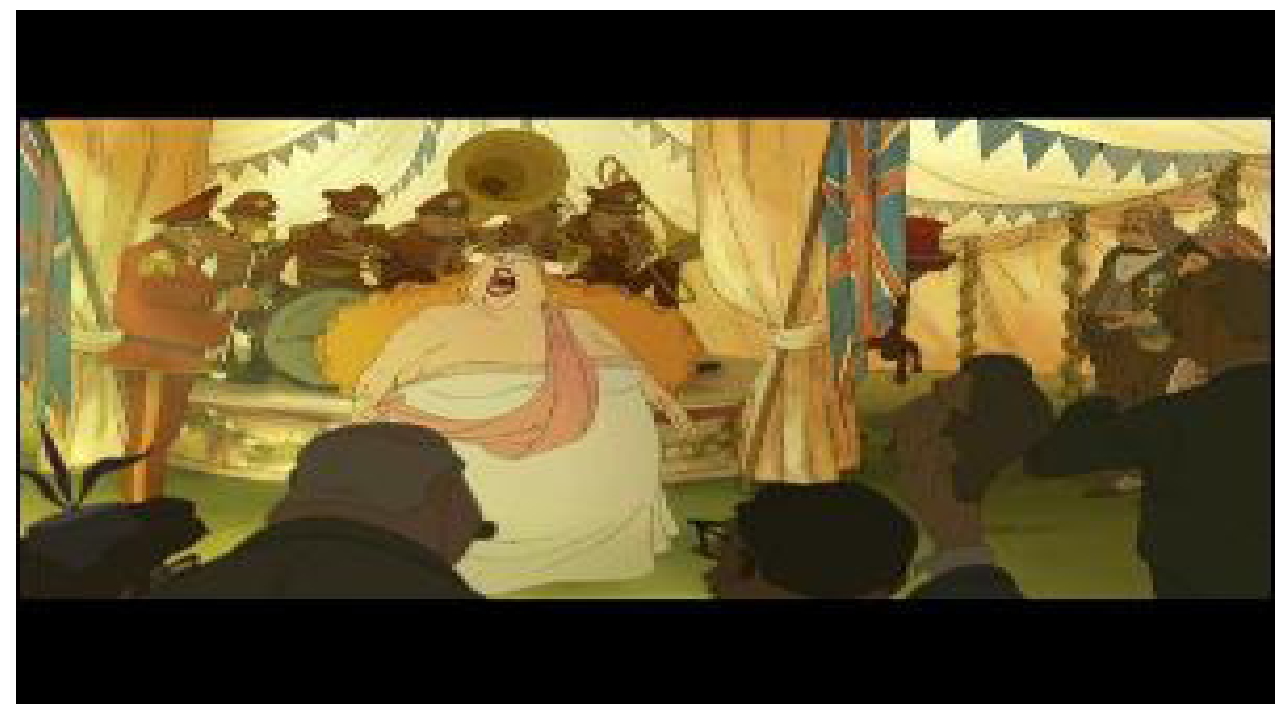

Figura 2 - Cena do Filme O Mágico

Fonte: The Internet Movie Database (2011)

A história se passa no ano de 1959, e a Europa representada na película vive a transição entre mundos diferentes dentro da modernidade: o mundo rural das diversões simples e da economia de sobrevivência e o mundo citadino, das diversões sofisticadas, do supérfluo e da abundância (para alguns); a transição do espetáculo tradicional para o novo espetáculo moderno, com seu foco transferido do espetáculo propriamente dito para o indivíduo e para a celebridade. E essas mudanças assimétricas dentro do moderno na sociedade trazem consigo, portanto e, sobretudo, o desconforto e o desconsolo que acompanham todas as transformações.

Ser moderno é encontrar-se em um ambiente que promete aventura, poder, alegria, crescimento, autotransformação e transformação das coisas em redor - mas ao mesmo tempo ameaça destruir tudo o que temos, tudo o que sabemos, tudo o que somos. (BERMAN, 1986, p. 15) 
Marcelo de Castro Andreo

Seguindo este caráter melancólico, poético e lírico, riquíssimo em detalhes ilustrativos o filme de animação nos mostra o mundo pela perspectiva de um mágico fadado ao esquecimento.

\section{O Filme}

O ilusionista Tatischeff viaja de Paris a Edinburgo aceitando trabalho em casas de espetáculos sem, no entanto, conseguir atrair muitos espectadores. Em uma de suas paradas, nas highlands escocesas ele é seguido por uma jovem admiradora, a menina Alice, a quem trata como um filha à partir de então.

O velho mágico é um elemento obsoleto tentando encontrar o seu lugar e seu sustento onde somente há o espaço para o novo. E a cada parada em sua trajetória ele se torna mais consciente de sua obsolescência e a incapacidade de entreter, de encantar e de fazer sua arte a provisão de seu sustento. Conforme Sennet (2000), a construção da identidade se dá em grande parte através do trabalho e - em uma sociedade onde as relações de trabalho proletarizadas são a regra - do emprego e da profissão.

Quando a profissão de mágico deixa de ter seu antigo brilho e não possibilita ao seu profissional a chance de tê-la como fonte de sua renda, de seu status na sociedade, a sua própria identidade está em jogo. Se a construção da individualidade se dá através da inserção no trabalho, com o desaparecimento da profissão esta mesma individualidade também está condenada ao desaparecimento.

No final do século dezenove e no início do século $X X$, as pessoas ainda podiam se encantar com as várias atrações das feiras, com as quermesses e suas pequenas aparições, jogos e divertimentos de pouco investimento, artistas de circo e artistas mambembes. Ainda se assistiam às apresentações de lanterna mágica e o público ainda podia se deliciar com as histórias contadas por estes lanternistas (MANNONI, 2003).

O mágico pertence a esse tempo, e em sua juventude, ele mesmo deveria ter sido o "novo" a sepultar as realizações da geração anterior, ainda que tivesse construído seu aprendizado e seu ofício sobre as bases oferecidas pelos seus antecessores. Na relação da obsolescência, o novo age como se o universo tivesse sido criado a partir de seu nascimento e tudo o que veio antes fosse apenas história sem relação com sua existência atual, como se se tratasse de um feito a-histórico e independente, que se construiu por si próprio. No ano de 1959, quando se passa a história do filme, o espetáculo do ilusionista já não chama a atenção da plateia e tem que competir com os novos entretenimentos urbanos, a televisão e o rock and roll.

As bandas de rock, os atores e atrizes de cinema, como Audrey Hepburn, que inspira o dispendioso figurino da campesina escocesa Alice, pelo menos aos olhos de seu público, vivem o eterno momento presente, onde são admirados ao ponto da histeria coletiva. $C$ consumo do espetáculo não se esgota quando este chega ao fim, e estende-se através do consumo de roupas e do estilo de vida até onde o dinheiro puder dar-lhe a sobrevida. $O$ show de mágica acaba-se ao fim dos truques, quando a caixa de mágicas é fechada e seu show, desde então, será a atração secundária, que não impressiona mais ninguém e que não consegue prolongar sua magia ao fim de tudo, pois não se encaixa na publicidade e no marketing do novo entretenimento. $\mathrm{O}$ mágico é um ingrediente do moderno que já se foi, antiquado, e deve dar lugar o moderno que "é".

Nesse ambiente [dos bulevares], a realidade facilmente se tornava mágica e sonhadora. As luzes ofuscantes da rua e do café apenas intensificavam a alegria:

Projética Revista Científica de Design I Universidade Estadual de Londrina I V.2 I N.1 I Junho 2011 
A encenação e a melancolia em "O Mágico"

nas gerações seguintes, o advento da eletricidade e do neon só faria aumentar tal intensidade (BERMAN, 1986, p. 149).

Os truques de mágica já não são segredos e aquilo que muito impressionou em um passado recente, agora só consegue arrancar bocejos de sua plateia. Isso fica bastante evidente na cena em que, num teatro praticamente vazio, uma senhora de idade assiste ao show de mágica com seu neto. Enquanto a senhora me mostra extasiada com as mágicas, seu neto procura explicar-lhe que o lenço do mágico esteve o tempo escondido dentro da manga de seu paletó. São dois pensamentos distintos: a da senhora que não deseja descobrir o artifício por trás de seu entretenimento e o menino, que desvenda e observa racionalmente. Como assinala Berman (1986, p. 152), no moderno ocorre à dessacralização, em que heróis passam a anti-heróis e a solenidade que podem carregar em si está reduzida ao burlesco, ao pastelão e a pantomima.

A animação em vários momentos trata das mudanças de comportamento a partir do encontro de realidades antagônicas, em certo sentido, mas complementares em outro. Existem as diferenças entre os mundos da agricultura e dos antigos espetáculos e o mundo urbano, industrial, das novas diversões e do culto à personalidade. Entretanto, esta nova configuração se constitui uma continuidade da anterior, um processo que se deu paulatinamente, resultado da reorganização do trabalho, da produção e das relações sociais decorrentes desta reorganização.

Deste modo, ainda que o llusionista Tatischeff esteja sofrendo com sua obsolescência frente ao novo, ele representa a introdução da novidade e do moderno na vida de sua protegida. Assim como a plateia rural das highlands, ela também se diverte com seus truques e consegue se impressionar com uma novidade (para si), que já é uma lembrança de um tempo que aparenta ser remoto, ainda que não o seja. Ela, assim como os aldeões, representa um estágio primeiro do moderno, ainda inextricavelmente ligado com o rural e no qual a cultura citadina não está em oposição à urbana. O ilusionista é quem traz os alentos de um mundo novo, com novas músicas, novos comportamentos e novas formas de consumo que servem para construir a identidade humana. É ele quem traz o século XX urbano para a vida da garota e a afasta do século XX rural, dos espetáculos de rua e da economia de subsistência.

Essa transição no tempo é revisitada em diversas ocasiões durante o filme, nas longas panorâmicas em 3D sobre paisagens pintadas a mão com aparência de aquarela. Nessas visões amplas, além de propiciar o conhecimento da audiência quanto à localização da história e as andanças de um lado para outro da Europa, o diretor permite que tanto espectador quanto personagens tomem distância do momento atual e vejam sua história integrada em um significado mais amplo, conectando os pontos do passado, presente e futuro: a duração individual do personagem e o transcorrer do tempo na sociedade.

Para o ilusionista parece não haver surpresas na cidade moderna: edifícios, tevês, lojas de departamento e teatros; nada disso altera a sua disposição fleumática. Não obstante a sua obsolescência como trabalhador no auge de sua força produtiva, de sua caminhada para o esquecimento como recreador das massas e de sua idade que avança, sua reação é a apatia pelo que as novidades do entretenimento podem representar. Enquanto isso, sua protegida, Alice, jovem em idade, encontra-se extasiada pelas atrações da cidade. Os dois personagens juntos, constituem a contradição apontada por Berman na atitude de Benjamim:

[...] os escritores parisienses de Benjamim constituem uma performance notavelmente dramática, surpreendentemente similar ao Ninotchka de Greta Garbo. Seu coração e sua sensibilidade o encaminharam de maneira irresistível para as luzes brilhantes da cidade, as belas mulheres, a moda, o luxo, seu jogo 
de superfícies deslumbrantes e cenas grandiosas; enquanto isso, sua consciência marxista esforçou-se por mantê-lo a distância dessas tentações, mostrou-lhe que todo esse vazio luminoso é decadente, viciado, espiritualmente vazio, opressivo em relação ao proletariado, condenado pela história. Ele faz repetidos comentários ideológicos para não ceder a tentação parisiense - e para evitar que seus leitores caiam em tentação - , todavia não resiste a lançar um último olhar ao bulevar ou às arcadas; ele quer ser salvo, porém não há pressa". (BERMAN, 1986, p. 142)

A menina, que pode ser considerada a típica flaneur, anda pelas ruas de Edimburgo, enamorada das vitrines e dos símbolos da moda e da beleza. Assim como Walter Benjamim, ao discorrer sobre Paris, a personagem também se deslumbra pelas atrações da grande cidade moderna. Ela não tem pressa nenhuma, pois seu sustento e seus presentes vêm de uma fonte mágica, que pode ser uma cartola ou por detrás da orelha. Terminadas as atividades de limpeza do pequeno quarto de hotel, ela pode dedicar-se ao passeio, com tanto sossego quanto o flaneur de Benjamin:

Ocasionalmente o pedestre sabia exibir de modo provocante sua nonchalance. Por volta de 1840 foi moda, durante algum tempo, conduzir tartarugas atreladas pelos "passeios", O flaneur gostava de marcar o seu ritmo por elas. Se fosse por ele, o progresso deveria ter esse passo. Mas não lhe coube a última palavra, mas antes a Taylor, que fez do combate à flânerie uma palavra de ordem (BENJAMIM, 1980, p. 41).

Mesmo ela, admirada pelos encantos da cidade, caminha para fora das avenidas em direção ao campo, de chão verde como a sua terra natal. É de lá que ela pode ver a diferença entre sua antiga morada e a atual; a transição entre os hábitos e modus vivendi rurais cheios de novecentismo para o pleno modernismo do século XX, que iguala as grandes cidades a partir de um modelo universal previamente constituído:

[...] No nível da rua, elas se enfileiravam em frente a pequenos negócios e lojas de todos os tipos e, em cada esquina, restaurantes com terraços e cafés nas calçadas. Esses cafés, como aquele onde os amantes baudelairianos e a família em farrapos se defrontaram, passaram logo a ser vistos, em todo o mundo, como símbolos de la vie parisienne. As calçadas de Hausmann, como os próprios bulevares, eram extravagantemente amplas, juncadas de bancos e luxuriosamente arborizadas. Ilhas para pedestres foram instaladas para tornar mais fácil a travessia, separar o tráfico local do tráfico de longa distância e abrir vias alternativas para as caminhadas. Grandes e majestosas perspectivas foram desenhadas, com monumentos erigidos no extremo dos bulevares, de modo que cada passeio conduzisse a um clímax dramático. Todas essas características ajudaram a transformar Paris em um espetáculo particularmente sedutor, uma festa para os olhos e para os sentidos. [...] Por volta de 1880, os padrões de Hausmann foram universalmente aclamados como o verdadeiro modelo de urbanismo moderno. Como tal, passou a ser reproduzido em grandes cidades de crescimento emergente, em todas as partes do mundo, de Santiago a Saigon (BERMAN, 1986, p. 147).

Quando o mágico devolve o coelho à natureza, ele próprio questiona a capacidade dele e de seu companheiro de palco de se adaptarem aos tempos modernos. O animal pertence ao campo ou ao tempo em que a distinção da cidade era apenas um borrão, e o ilusionista, de uma cidade que se distinguia muito da atual, na qual ele era o provedor do espetáculo, da surpresa e da irreverência.

Tati, em Mon Oncle também retrata a perplexidade e a apatia que convivem perante as 
A encenação e a melancolia em "O Mágico" novidades do moderno: o uso onipresente do plástico, a sociedade automotiva, a arquitetura desumanizada, o mobiliário funcionalista e a reapropriação das vanguardas artísticas como produtos de consumo. Um padrão de vida bastante afastado dos sapatos rotos de uma vida inteira e o vestido continuamente reutilizado da menina pobre, típicos de um sistema em que o uso estava ligado a preservação da utilidade e nem tanto aos ditames da moda ou da obsolescência programada.

\section{A encenação}

O Mágico não apenas remete ao inevitável conflito entre o novo e o antigo dentro de sua narração e da relação entre os personagens. Além do roteiro está a escolha estilística que, tanto homenageia a mise-en-scène típica dos filmes de Tati, quanto traz para o contexto do filme o plano "praticamente" em forma de tableaux ou quadro de filmes anteriores à década de 1950 (lembrando-se que o filme se passa no final desta década).

Em outras palavras, a encenação ou staging, como é chamada no jargão do cinema de animação, acontece dentro de quadros fixos (os tableaux) em detrimento da continuidade clássica hollywoodiana, que privilegia a montagem e a sucessão de planos. Chomet constrói a história privilegiando o plano de longa duração. É óbvio que há centenas de planos, como se poderia esperar de qualquer filme de longa metragem; no entanto, a forma de encadear os acontecimentos não está somente na sequência de planos, por exemplo: um plano geral para localização e planos médios e closes para a atuação dos personagens. O plano primordial do filme é o plano de conjunto, mostrando os personagens de corpo inteiro, e as várias atitudes dos personagens ocorrem dentro de um mesmo plano, conduzidas com sutileza mediante o uso deliberado da luz, da cor e da movimentação dos personagens dentro do quadro. Como diz Bordwell (2008, p. 33) "a tendência do diretor de mise-en-scène é minimizar o papel da montagem, criando significado e emoção principalmente por meio do que acontece dentro de cada plano".

Se o cinema mainstream opta pela continuidade hollywoodiana, a montagem acelerada e o uso ostensivo do campo e contracampo, Chomet faz uma escolha "anacrônica" pelo plano de conjunto e a mise-en-scène. As possíveis razões para essa decisão estilística derivam da fidelidade do diretor à sua homenagem à Tati e ao modo europeu do cinema mudo:

\footnotetext{
Enquanto o cinema americano diminuía a duração dos planos e apoiava-se em atuações mais contidas e realistas, os cineastas europeus usavam cenários elaborados e realizavam atuações complexas dentro deles. Criavam ambientes com várias camadas, cheios de portas e aberturas que deixavam ver as salas adjacentes onde parte das ações era encenada (COSTA, 2006, p. 48).
}

O mágico Tatischeff, a menina Alice e os demais personagens atuam praticamente sem o uso de diálogos. As poucas falas que existem são tão abafadas e mal pronunciadas que parecem mais ruídos, e isso também faz parte das opções do diretor: a ênfase está na pantomima, na expressão corporal e na movimentação dos atores pelo "palco". Tal e qual nos filmes mudos, onde a câmera permanecia fixa e o plano sequência não era uma alternativa, mas a única forma de se contar uma história no cinema. Com a câmera parada num único local, como um observador numa plateia de teatro, tinha-se um tableau, com grande profundidade de campo, no qual os atores deveriam coreografar seus movimentos para que o espectador pudesse saber para onde olhar (BORDWELL, 2008; AUMONT, 2004). 
As gags do cinema mudo, em Chaplin ou Buster Keaton, aconteciam diante desse observador imóvel, com poucas mudanças de plano. Estes atores atuavam com o corpo todo e não necessitavam de closes para transmitir suas mensagens. O peso está contido na encenação complexa e não na edição. O cinema de continuidade clássica usaria mais planos médios e closes, além do campo e contracampo (BORDWELL, 2008, p. 45). No cinema mudo de Chaplin e Keaton, campo e contracampo e dezenas de intertítulos inviabilizariam a história, uma vez que não havia fala para completar a mensagem. Como os personagens de Chomet usam muito pouco da fala para contar sua história, a alternativa possível é contar através da encenação complexa e das ações secundárias dos personagens.

Outra característica do cinema mudo que reproduzida em O Mágico está a profundidade de campo alta. A profundidade alta permite que se perceba o inimigo ou qualquer outro personagem que se mova ao fundo, emoldurado por uma porta ou uma janela, ou ocupando um espaço vago do quadro deixado pelos personagens principais naquele momento. Movimentando os personagens do primeiro plano para o lado ou para o fundo, há a deixa para que esse outro elemento sugerido ou apenas sutilmente exposto seja enfim explicitado. $O$ virtuosismo da animação também pode ser auferido por meio da profundidade de campo. Como num quadro de Bruegel ou Bosch, pequenos detalhes estão em todos os lugares para serem observados, e ainda que não contem a história principal, eles estarão lá para a segunda, terceira ou quarta vez que o espectador parar diante da tela para assisti-los. Existem diversas ações secundárias no estilo "ilusion of life" no que diz respeito ao movimento, porém com resultados gráficos bastante diferentes do padrão Disney.

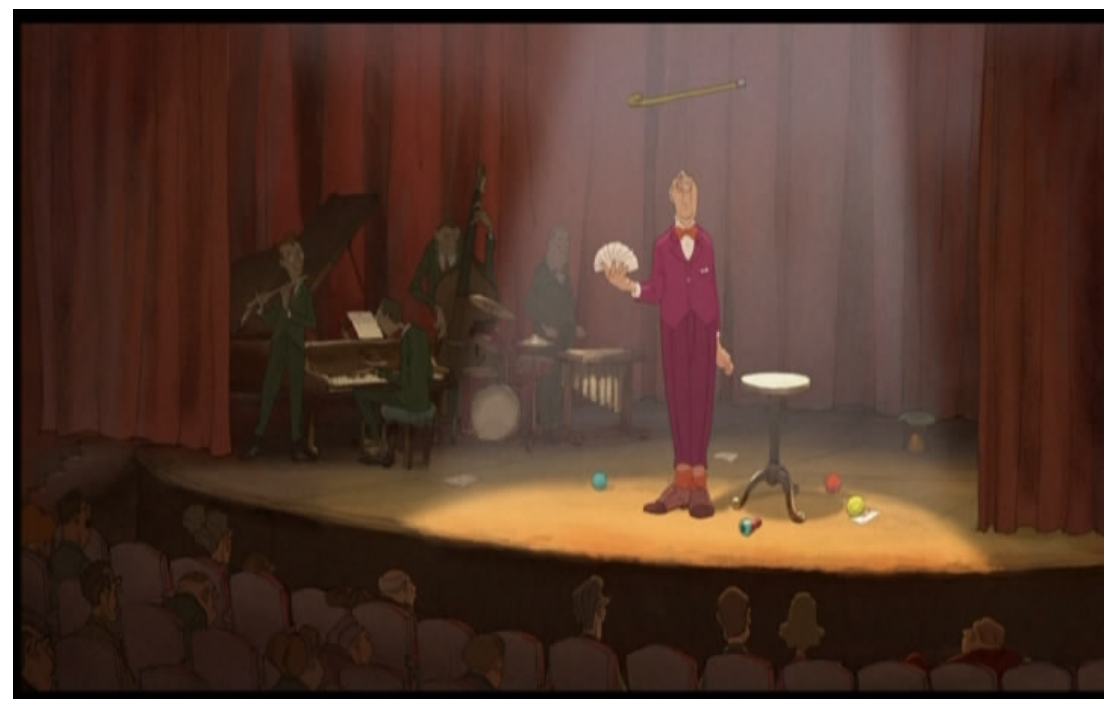

Figura 3 - Cena do Filme O Mágico

Fonte: The Internet Movie Database (2011)

No desenho animado, se o autor desejar, tudo pode estar no foco da "câmera". Não há a limitação do equipamento em focar uma parte da imagem e deixar o restante desfocado.

A definição do que deve ou não ser apresentado e a simulação do desfoque, ou da baixa profundidade de campo fica a critério dos autores.

Na figura 3, nos minutos iniciais do filme, já podem verificar-se os recursos utilizados pela equipe de Chomet para contar a história de Tatischeff, o mágico. A câmera não tem o enquadramento clássico dos tableaux, visto que trata-se de uma câmera alta (plongée) do lado direito da tela. No entanto, os outros elementos, bastante característicos do cinema mudo e de Jacques Tati estão lá: o plano de conjunto, enquadrando os personagens à distância, as ações

Projética Revista Científica de Design I Universidade Estadual de Londrina I V.2 I N.1 I Junho 2011 
A encenação e a melancolia em "O Mágico"

simultâneas e a alta profundidade de campo.

Enquanto Tatischeff faz seus truques, a pequena orquestra do lado esquerdo do quadro toca uma música. Os animadores criaram alguns ciclos para cada personagem e para algumas cabeças da plateia. Para que esses vários elementos animados não resultem em confusão, a cena é divida em planos com valores (gradação de luz) e cores diferentes. No primeiro plano, está a plateia com um valor de cinza mais escuro; no segundo plano, mais iluminado, está o mágico e, no terceiro, com um valor de cinza médio está a banda. Enquanto a maior parte do quadro encontra-se tingida por um tom vermelho-amagentado, Tatischeff está iluminado por uma luz branca, e torna-se mais perceptível no chão, tingido de amarelo ocre, contrastante com a cor de sua roupa.

A luz difusa tende a planificar as formas, produzindo normalmente formas e silhuetas padronizadas quando à chuva, neve ou nevoeiro denso. A luz plana e difusa é fria, não é quente nem solarenga, e é um excelente instrumento para produzir ambientes pesados, melancólicos ou de desespero (HOGARTH, 1999, p. 64).

A luz difusa também reduz a tridimensionalidade, e as gradações de distância (plano próximo, médio e distante) são atribuídas pelos valores de cinza e pela sobreposição dos objetos e personagens.

O desenho animado, para ter sua produção viabilizada, necessita cuidar desse aspecto. A luz difusa não é apenas uma escolha estilística e, sim, econômica. Uma animação para o cinema tem vinte e quatro quadros por segundo. Uma sombra ou uma pequena mancha que apareça em um segundo serão uma sombra e uma mancha que serão animadas vinte e quatro vezes (WHITE, 2006; BLUTH, 2004). Logo, sombrear ou criar nuances de cor no personagem não são escolhas econômicas adequadas: alguém precisará desenhar tudo isso. $O$ tempo é curto e os recursos limitados.

Conforme estão localizados nos diversos planos, os personagens recebem a luz difusa que marca aquele mesmo plano, como se tivessem sido tingidos por uma lente colorida (BLUTH, 2004; HOGARTH, 1999). Na figura 4, Tatischeff está num segundo plano, e se destaca com sua roupa violeta do fundo apenas pela saturação. O plano de fundo é o menos saturado de todos, em cinza colorido e permite uma ação paralela de uma atriz ao fundo, que se dirige à porta da direita, que serve para indicar que lá estão os bastidores.

Todo o filme está em tons pasteis tendendo para o amarelo e para os tons de ocre e terra aquarelados, de modo que o mágico passeie pelo cenário sem se confundir com ele.

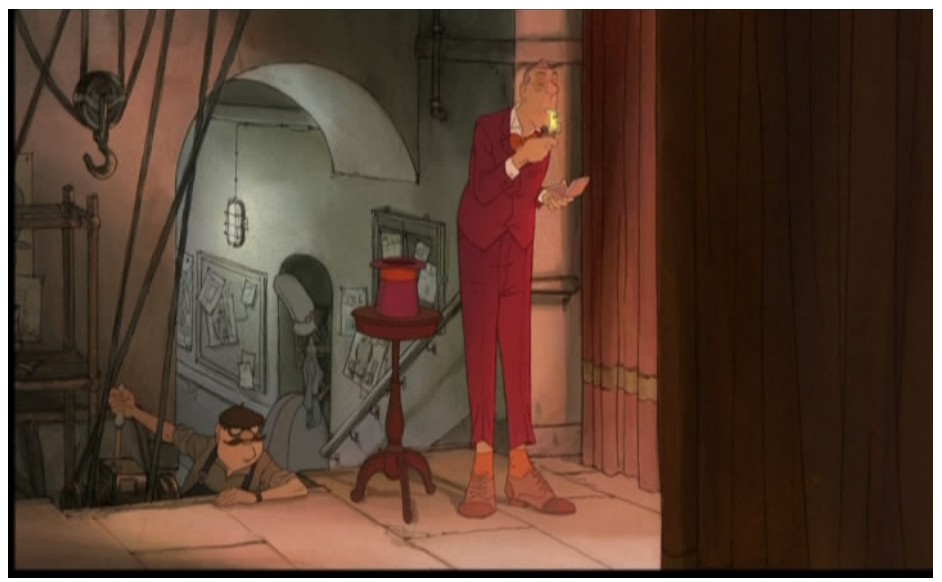

Figura 4 - Cena do Filme O Mágico

Fonte: The Internet Movie Database (2011)

Projética Revista Científica de Design I Universidade Estadual de Londrina I V.2 I N.1 I Junho 2011 
Os caracteres tendem a expressões faciais únicas e, como não há close, é a linguagem corporal somada ao posicionamento dentro do plano (staging) e com a inter-relação com os outros personagens que apresenta as personalidades do filme. A expressão das emoções no rosto de cada um deles é discreta e contida. Cada um deles tem uma reação quanto à novidade e às comunidades tradicionais. O simpático ébrio escocês (Fig. 5) mantém um sorriso constante e os olhos cerrados e faz a ponte entre os dois mundos: o rural e tradicional e o urbano e moderno. Ele está igualmente receptivo ao show do mágico e ao show das bandas de rock;

A menina Alice é toda maravilhamento, ainda que sua expressão fácil seja bastante limitada; Tatischeff está deslocado e apático, porém, sua fleuma não o impede de sentir as pequenas perplexidades durante as gags visuais.

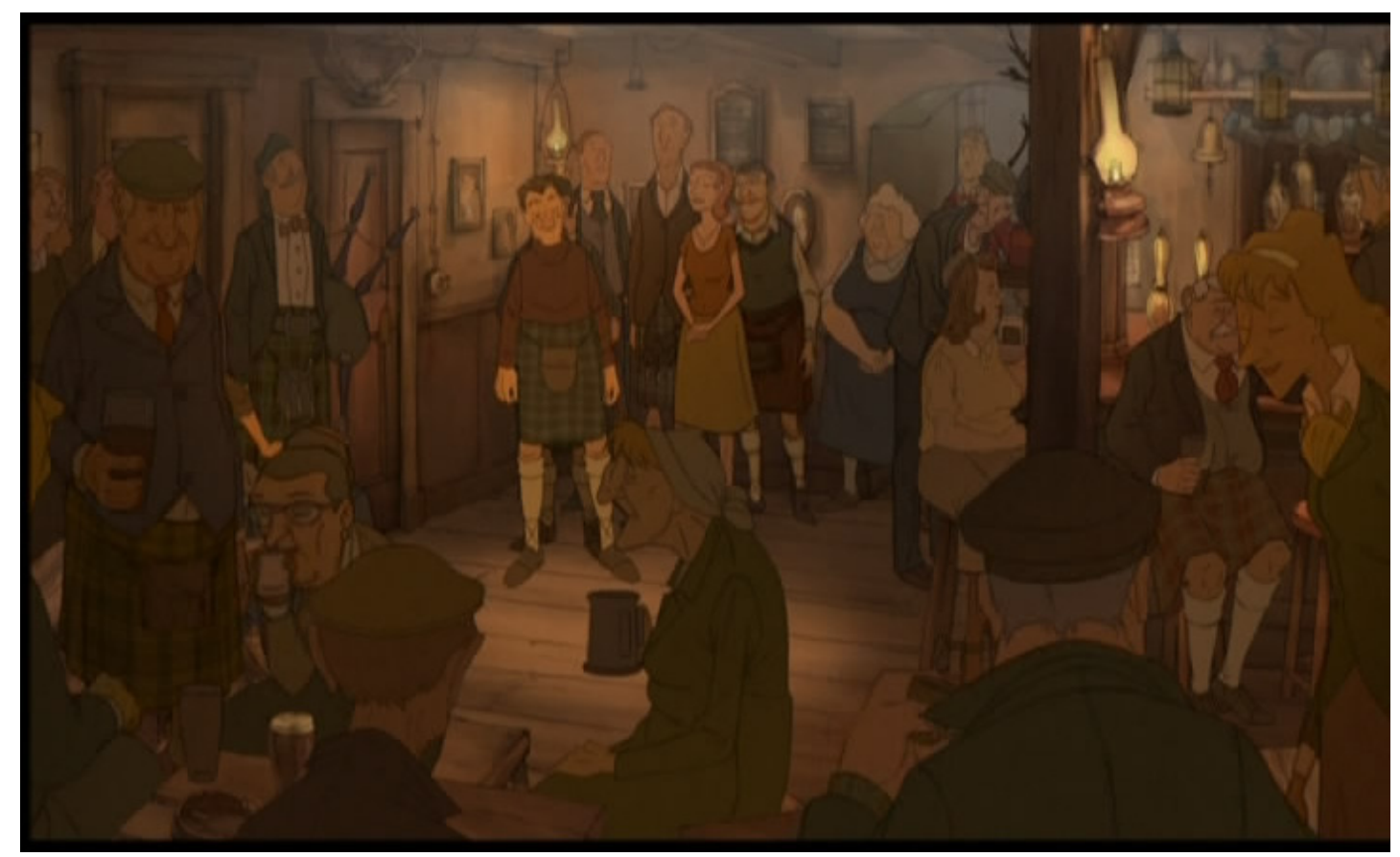

Figura 5 - Cena do Filme O Mágico

Fonte: The Internet Movie Database (2011)

Em todos os exemplos apresentados, o layout do cenário é composto por camadas de planos, normalmente três deles, bastante elaborados e repletos de elementos, como nas figuras 6 e 7. A escala básica dos valores também contém três variações de cinza, com o cinza mais escuro no primeiro plano, e os cinzas médio e claro revezando-se entre o segundo e o terceiro plano. Esse primeiro plano mais escuro pode ser uma cortina, uma peça de mobiliário ou uma parede e, apesar de ser maior do que os outros elementos, acaba sendo equilibrado por elementos menores que se encontram na extremidade oposta do quadro, como o rosto de Alice na figura abaixo, que equilibra o peso da cadeira à direita nesta composição. A camada que deve chamar a atenção está em cores quentes (novamente, a porta, o local de onde Alice está espiando o mágico), enquanto o resto do quadro tem tons mais frios.

Existem duas ações simultâneas: Alice espiando e Tatischeff arrumando sua camisa. Uma é mais importante do que a outra. A arrumação da camisa é corriqueira, e indica a atuação de Tatischeff, mas o interesse da garota é a ação relevante, e devido a sua importância está emoldurada pela porta, equilibra o peso na composição e está colorida com uma paleta quente. 


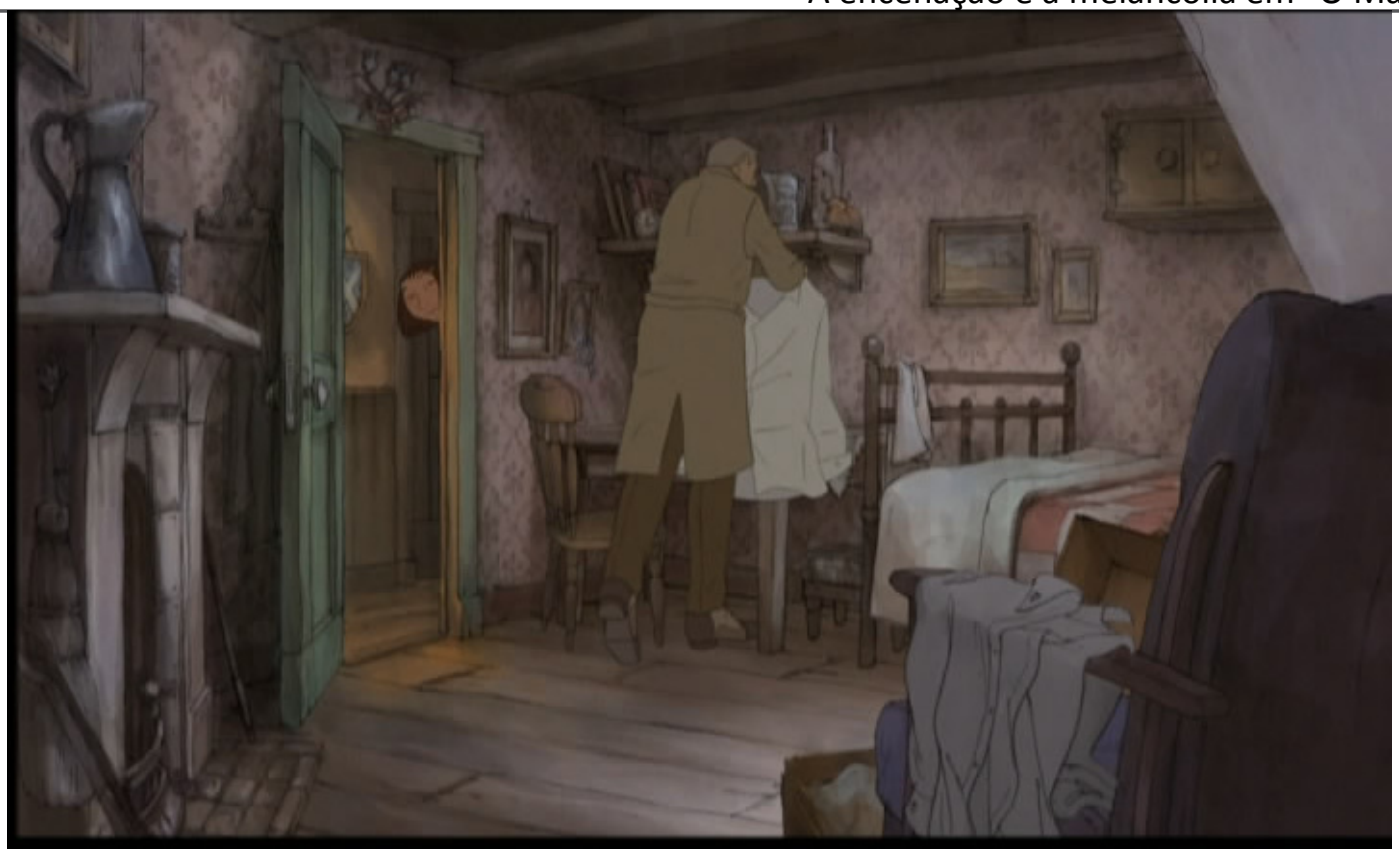

Figura 6 - Cena do Filme O Mágico

Fonte: The Internet Movie Database (2011)

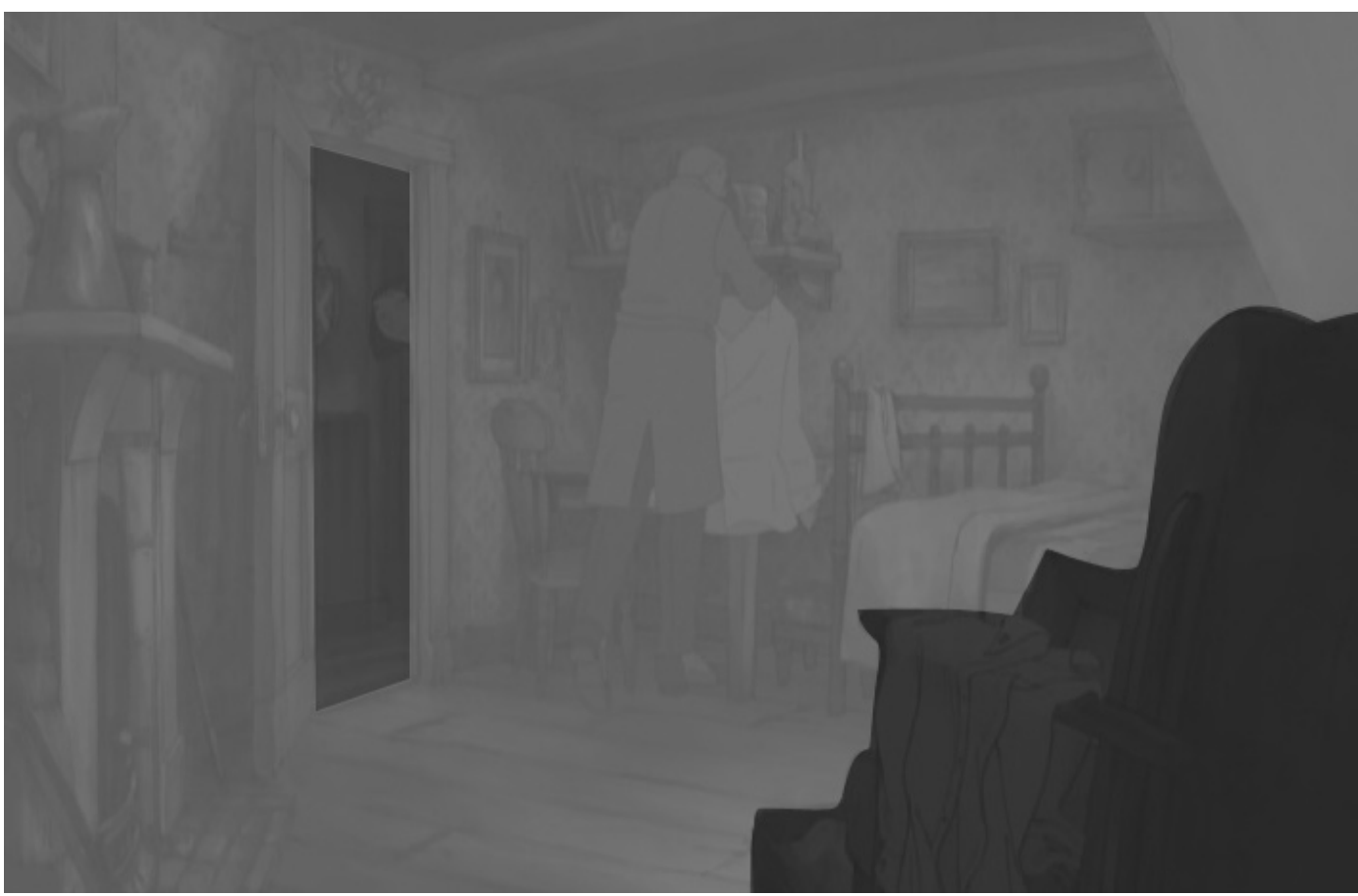

Figura 7 - Cena do Filme O Mágico

Fonte: The Internet Movie Database (2011)

\section{Considerações Finais}

As definições estilísticas do cineasta estão em conformidade com a problemática levantada. Para confrontar o cinema de continuidade norte-americano, está a encenação em profundidade do cinema mudo europeu e dos filmes de Jacques Tati. Contra a verborragia atual e os planos aproximados em campo/contracampo estão os quase inexistentes diálogos e 
Marcelo de Castro Andreo

a atuação dos personagens em tableaux. E para sobrepor-se ao cinismo dos filmes de animação pós-modernos, a melancolia que resulta do inocente maravilhamento da garota e da silenciosa desesperança do Mágico.

A encenação em profundidade na animação traz consigo problemas que eram inexistentes nos filmes em preto e branco. Não basta mover os personagens para que encubra um elemento e se mostre algum outro. Eles precisam ser ajustados na composição como se faria em uma ilustração de forma equilibrada, ressaltados ou escondidos por meio do jogo com os valores da iluminação e com a paleta de cores ora saturada e quente, ora dessaturada e fria. A trilha sonora auxilia a compor o clima entristecido do longa metragem, que a imagem por si só não conseguiria.

O cineasta Sylvain Chomet não procura somente contar uma história para alguns minutos de entretenimento. Há alguma mensagem a mais, uma discussão contida em sua história. Em seu filme anterior Bicicletas de Beleville, há o sarcasmo em torno da Belleville, a cidade da fartura, do consumo, das pessoas obesas e dos gangsters inescrupulosos. Em $\mathrm{O}$ Mágico, as cidades indicam, cada uma, o seu desencanto, o embate entre o antiquado e o atual; o que representava a alegria no passado, no momento atual a tristeza, a pobreza e a obsolescência, próprias de um sistema que precisa destruir para continuar existindo. A ironia de Chomet em O mágico está em sua utilização de técnicas "antiquadas" de cinema para narrar a história de uma atualidade que se constrói na evanescência e na busca infinita e infrutífera pela novidade.

\section{Notas}

${ }^{1}$ Os personagens de Chomet não são o que pode se chamar de bonitos. Chomet faz com que os rostos de seus atores sejam esticados, deformados, com alguns narizes imensos. Também não procura seguir a tendência cartoon retrô que as animações mainstream de tevê costumam seguir.

\section{Referências}

AUMONT, Jacques. O olho interminável: cinema e pintura. São Paulo: Cosac \& naify, 2004.

BENJAMIM, Walter. Sobre alguns temas em Baudelaire. In: BENJAMIM, Walter; HORKHEIMER, Max; ADORNO, Theodor W.; HABERMAS, Jurgen. Textos escolhidos. São Paulo: Abril Cultural, 1980. p. 29-56.

BERMAN, Marshall. Tudo que é sólido desmancha no ar: a aventura da modernidade. São Paulo: Companhia das Letras, 1986.

BLUTH, Don. Don Bluth's Art of Storyboard. Milwaukie: DH Press, 2004.

BORDWELL, David. Figuras traçadas na luz: a encenação no cinema. Campinas: Papirus, 2008.

COSTA, Flávia C. Primeiro cinema. In: MASCARELO, Fernando (Org.). História do cinema mundial. Campinas: Papirus, 2006. p. 17-52

HOGARTH, Burne. Luz e Sombra sem dificuldade. Nova York: Evergreen, 1999.

MANNONI, Laurent. A grande arte da luz e da sombra: arqueologia do cinema. São Paulo: UNESP, 2003.

SENNET, Richard. A corrosão do caráter. Rio de Janeiro: Record, 2000.

THE INTERNET MOVIE DATABASE. O mágico. Disponível em:<http://www.imdb.com/ title/ 
tt0775489/>. Acesso em: 1 maio 2011.

WHITE, Tony. Animation from pencils to pixels: classical techniques for digital animators. Oxford: Focal Press, 2006. 